\title{
Improved Immuno-Detection of a Low-Abundance Cyclophilin Allows the Confirmation of its Expression in a Protozoan Parasite
}

\author{
Patricia L Bustos ${ }^{1^{*}}$, Alina E Perrone ${ }^{1}$, Natalia A Milduberger ${ }^{1,2}$ and Jacqueline Bua ${ }^{1,2}$ \\ ${ }^{1}$ Instituto Nacional de Parasitología "Dr. Mario Fatala Chabén"- A.N.L.I.S. Malbrán, Av. Paseo Colón 568, C1063ACS, Buenos Aires, Argentina \\ ${ }^{2} \mathrm{CAECIHS}$, Universidad Abierta Interamericana, Av. Montes de Oca 745, $2^{\circ}$ piso, C1270AAH, Buenos Aires, Argentina.
}

\begin{abstract}
Protein samples can be challenging to analyze due to the presence of high-abundance proteins masking lowabundance proteins of interest, such as biomarkers and novel physiological mediators. Cyclophilins are chaperones involved in the cis/trans isomerization of peptidyl-prolyl bonds in peptides or proteins and have been found in every organism sequenced to date. Although considerable progress has been made in the characterization of some cyclophilins expressed in diverse parasites invading humans, the main aspects of low-abundance members of this family remain unknown. In the present work, we present that the combined strategy of using more specific antibodies and increasing the presence of subcellular proteins in the sample, allowed us to confirm the expression of a $21.1 \mathrm{kDa}$ cyclophilin for the first time in Trypanosoma cruzi.
\end{abstract}

Keywords: Low-abundance proteins; Subcellular fractionation; Anti-synthetic peptides antibodies; Cyclophilins; Trypanosoma cruzi

\section{Introduction}

Cyclophilins (CyPs) catalyse the cis/trans isomerization of peptidyl-prolyl bonds in peptides or proteins (PPIase activity) $[1,2]$. Genomes of some prokaryotes, reviewed by Galat [3] and all sequenced-to-date eukaryotes encode from one to several different paralogues of cyclophilins. Their nominal masses may vary from about $17 \mathrm{kDa}$ (monodomain CyP) to several hundred $\mathrm{kDa}$. CyPs have been localized to different cellular compartments, namely the cytoplasm [4], the membranes and mitochondria [5], the endoplasmic reticulum [6], the secretory pathway [7], the spliceosome [8], the nucleus and its membranes [9-11].

The archetypal CyP of the family is CyPA, which has been discovered as a cyclosporin A (CsA) [12] binding protein [4]. More than 20 paralogues of $\mathrm{CyPA}$ are expressed in the human body while expression levels and functions of numerous ORFs encoding cyclophilin-like sequences remain unknown. For example, CyPA and a $40 \mathrm{kDa}$ multidomain cyclophilin ( $\mathrm{CyP}-40)$ have been isolated in sizable quantities which indicate that some members of the cyclophilin family of proteins are abundantly expressed in different mammalian organs $[4,13,14]$. However, other members of the cyclophilin family may represent a challenging sample to analyze as the protein concentration range spans a few orders of magnitude and organellar proteins are generally low-abundance proteins which are extremely difficult to detect in complex samples.

Although considerable progress has been made in molecular characterization of some cyclophilins expressed in diverse parasites invading humans [15], the knowledge of functional aspects of the differentiated repertoires of the cyclophilins expressed in numerous parasites remains scarce $[15,16]$.

Trypanosoma cruzi is the protozoan parasite that causes Chagas disease or American trypanosomiasis. This is a potentially lifethreatening illness and it is estimated that about 7 million to 8 million people are infected, mostly in Latin America, where Chagas disease is endemic, but also in other parts of the world through migration from endemic areas (WHO, 2014). The Trypanosoma cruzi cyclophilin gene family comprises 15 paralogues whose nominal masses vary from
19 to $110 \mathrm{kDa}$, but only the 4 of them with high abundance could be isolated from T. cruzi epimastigote extracts by cyclosporin A-affinity chromatography [16].

In recent years, several studies have described additional cellular functions for cyclophilins, including roles as chaperones and in cell signaling. Therefore, cyclophilins have proved to be of potential interest in elucidating physiological processes that still remain unknown.

Enrichment in low abundance proteins has become a challenge in the search of biomarkers and mediators. Efforts have been made in characterizing protein profile of biological samples such as placenta [17], urine [18] plants [19], etc. The techniques applied to this goal are diverse and include protein depletion and mass spectrometry $[17,20]$, improved fractionation and purification methods [18], high-resolution NMR [21] among others.

Improving the detection of low-abundance proteins is also a challenge when characterizing molecules in human pathogens. The search on novel molecules to identify new drug targets and also to improve the knowledge about the biology of these microorganisms is under development, supported by improved strategies and new technologies.

In this work, we present an effective strategy for enrichment in low-abundance parasite CyPs to levels that enabled the immunological detection with more specific antibodies. This approach allowed us to identify for the first time the expression of a cyclophilin localized to the endoplasmic reticulum of the parasite.

*Corresponding author: Patricia L. Bustos, Instituto Nacional de Parasitología "Dr. Mario Fatala Chabén". Av. Paseo Colón 568 C1063ACS, Ciudad Autónoma de Buenos Aires, Argentina, Tel: +54 114331 4019; E-mail: pato54mar@yahoo.com.ar

Received September 16, 2015; Accepted October 01, 2015; Published October 06, 2015

Citation: Bustos PL, Perrone AE, Milduberger NA, Bua J (2015) Improved Immuno-Detection of a Low-Abundance Cyclophilin Allows the Confirmation of its Expression in a Protozoan Parasite. Immunochem Immunopathol 1: 103. doi: 10.4172/2469-9756.1000103

Copyright: (c) 2015 Bustos PL, et al. This is an open-access article distributed under the terms of the Creative Commons Attribution License, which permits unrestricted use, distribution, and reproduction in any medium, provided the original author and source are credited. 
Citation: Bustos PL, Perrone AE, Milduberger NA, Bua J (2015) Improved Immuno-Detection of a Low-Abundance Cyclophilin Allows the Confirmation of its Expression in a Protozoan Parasite. Immunochem Immunopathol 1: 103. doi: 10.4172/2469-9756.1000103

\section{Experimental Section}

\section{Parasites}

T. cruzi CL Brener clone parasites were cultured in biphasic medium containing $1.5 \%$ nutrient agar with the addition of $0.2 \%$ rabbit defibrinated blood and Brain Heart Infusion medium (Difco Michigan, USA). Epimastigotes were collected at 5 days of culture (late log phase) at $28^{\circ} \mathrm{C}$.

\section{Antibodies anti-TcCyP21 synthetic peptide}

From TcCyP21 protein sequence (GenBank Acc. Number KP792643) two specific peptides were synthesized: P1NTKTGLNDKPKKC y P2 - VSARADPVVTD (Sigma Co., USA) and coupled to KLH carrier protein by standard procedures. Balb/c mice were immunized with five intra-peritoneal doses of KLH coupled peptide $(10 \mathrm{mg} / \mathrm{ml}$ each) with Freund's incomplete adjuvant to raise anti-mouse specific polyclonal antibodies.

\section{Subcellular fractionation}

To increase the concentration of organellar proteins in the sample, cell fractionation was performed following a described protocol [22]. Briefly, T. cruzi epimastigotes were washed three times in $15 \mathrm{ml}$ MES buffer (20 mM MOPS, pH 7.0, $250 \mathrm{mM}$ sucrose, $3 \mathrm{mM}$ EDTA). The cell pellet was resuspended in $0.2 \mathrm{ml}$ MES buffer containing $4 \mathrm{mg} /$ $\mathrm{ml}$ digitonin and protease inhibitors: $1 \mathrm{mM}$ pepstatine $\mathrm{A}, 1 \mathrm{mM}$ phenylmethylsulfonylfluoride (PMSF) and $0.1 \mathrm{mM}$ Na-ptosyl-Llysine chloromethyl ketone (TLCK). The suspension was incubated at room temperature for $5 \mathrm{~min}$ and centrifuged at $10,000 \mathrm{~g}$ for $5 \mathrm{~min}$. The resulting supernatant was collected as a cytosolic fraction, and the heavy membrane enriched pellet (membrane-enriched fraction) was resuspended in phosphate buffer $(20 \mathrm{mM}$ sodium phosphate, $\mathrm{pH} 7.0$, 3 mM EDTA).

\section{SDS-PAGE and western blot analysis}

Procedures for SDS-PAGE of protein samples were carried out as described by Laemmli [23]. $10^{7}$ parasites per lane were loaded for total parasite lysate. For subcellular fractionation, $10^{8}$ parasites were treated with digitonin and the whole volume of the membrane-enriched fraction was loaded per lane. Polypeptides were electro-transferred from $13.5 \%$ polyacrylamide gels to nitrocellulose membranes (Whatman International Ltd., Germany), which were blocked with a $5 \%(\mathrm{~W} / \mathrm{V})$ non-fat milk suspension for $1 \mathrm{~h}$ at room temperature. After overnight incubation for $2 \mathrm{~h}$ with a mouse polyclonal antibody against peptide 1 (P1) or peptide 2 (P2) from TcCyP21, membranes were thoroughly washed with PBS-Tween $0.05 \%$. A biotinylated antimouse (1:2000) was used as a secondary antibody and streptavidinhorseradish peroxidase (1:1000) was used to enhance the signal. Proteins were visualized by with an ECL Western Blotting Detection kit (GE Healthcare).

\section{Immunofluorescence microscopy}

To determine the localization and expression of TcCyP21 in T.cruzi, live epimastigotes were labelled with Mitotracker Red (Invitrogen) at $50 \mathrm{nM}$ in PBS-3\% glucose for $30 \mathrm{~min}$ at $28^{\circ} \mathrm{C}$. Epimastigotes were washed in ice-cold PBS and fixed with $1 \%$ paraformaldehyde in PBS at $4^{\circ} \mathrm{C}$ for $1 \mathrm{~h}$. The fixed parasites were washed twice with PBS, allowed to adhere to poly-L-lysine-coated coverslips and permeabilized with $0.1 \%$ TritonX-100/PBS for $5 \mathrm{~min}$. After blocking with PBS containing 3\% BSA for $1 \mathrm{~h}$ at room temperature, epimastigotes were incubated with 3\% BSA/PBS with anti-P1-TcCyP21 (1:100) for $1 \mathrm{~h}$. After thoroughly washing with PBS, parasites were stained with Alexa 488-conjugated goat anti-mouse antibody at 1:1,000 for $1 \mathrm{~h}$. Parasites were mounted with Vectashield (Vector Labs) containing DAPI as DNA staining. Images were obtained with an Olympus DP72 camera coupled to a fluorescence microscope Olympus BX60 and analyzed with Image J software.

\section{Results}

\section{Peptide selection for specific antibodies}

In Trypanosoma cruzi genome there is a sequence for a $21.1 \mathrm{kDa}$ cyclophilin (GenBank Acc. Number KP792643) named TcCyP21. This protein has a predicted signal peptide of $28 \mathrm{AA}$ and it was inferred to be transcribed in different cell cyle stages: epimastigotes (AI562688, AI562266) [24] and also in trypomastigote and amastigote cDNA 132 libraries (CF889418, CB923590) [25]. However, the transcription of $T c \mathrm{CyP} 21$ could not be confirmed by cyclosporin A-affinity chromatography [16].

To evaluate if its expression could be detected by Western blot, antibodies against specific peptides of $T c \mathrm{CyP} 21$ protein were raised. To this end, we analyzed the TcCyP21 protein sequence with Bepipred$1.0 \mathrm{~b}$, a free server that allows choosing the most immunogenic regions within an aminoacidic sequence [26]. Of the four peptide options that were identified by the server, two were synthesized, considering both the immunogenicity and the unconserved region of the sequence among the CyP family (Figure 1).

After obtaining the immune sera against each synthetic peptide, they were tested by Western blot against the recombinant protein available in our laboratory. We observed that while the antibodies against $\mathrm{P} 1$ were able to detect the recombinant $T c \mathrm{CyP} 21$, this was not the case with the anti-P2 antibodies (Figure 2).

We continued our studies with the immune serum against peptide 1 from $T c \mathrm{CyP} 21$, identified as anti-P1.

\section{Anti- P1 was able to detect the native TcCyP21 in a membrane- enriched fraction}

To evaluate if we could confirm the expression of native TcCyP 21 by Western blot, we prepared two different protein samples. One of them was total parasite lysate and the other corresponded to a membraneenriched fraction (as described in the Experimental Section) to try to increase the presence of low-abundance organellar proteins. We observed that $\mathrm{TcCyP} 21$ could not be detected by anti-P1 in a total parasite lysate. However, when we enriched the sample in organellar membrane proteins (without most of the high-abundance cytosolic proteins), anti-P1 was able to detect a unique band of the expected size for TcCyP21 (Figure 3A).

It is important to highlight that the antibodies against the whole recombinant $T c \mathrm{CyP} 21$, failed to detect a unique band against these samples, probably by cross-reacting with the conserved regions of other members of the cyclophilin family (Figure 3B).

\section{Anti- P1 reveals the native $T c C y P 21$ subcellular localization by immunofluorescence}

To confirm subcellular localization of $T c \mathrm{CyP} 21$, we performed immunofluorescence using the anti-P1 antibodies against the epimastigote stage of the parasite. We also used Mitotracker Deep Red as a mitochondrial marker and DAPI as nuclear staining.

We observed that $T c \mathrm{CyP} 21$ presented perinuclear distribution, 
Citation: Bustos PL, Perrone AE, Milduberger NA, Bua J (2015) Improved Immuno-Detection of a Low-Abundance Cyclophilin Allows the Confirmation of its Expression in a Protozoan Parasite. Immunochem Immunopathol 1: 103. doi: 10.4172/2469-9756.1000103

\section{MRYLLLSKVTQLLLLLLLMLFAAVSARADPVVTDKV YFDITIGDEPVGR VVIGLFGNDVPKTVKNFKQLASGENGFG YKGSIFHRVIRNFMIQGGDETN FDGT GGKSIY GARFDDENLKIKHFV GAV SMANA GPNSNGSQFFVTT APT PWLDGRHVVFGKVVEGMDVVKK VENTKT GLNDKPNKA VKINDCGVL}

Figure 1: Selection of immunogenic peptides from TcCyp21. The search for immunogenic sequences present in TcCyP21 was performed using the Bepipred $1.0 \mathrm{~b}$ free server. The program suggested 4 peptides, which were classified as best epitopes (bold), very good epitopes (box) and good epitopes (underlined). Finally, the 2 peptide sequences that did not align with the conserved region were chosen for antibodies raising.

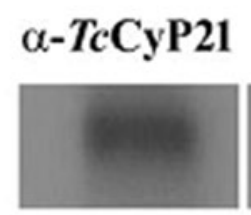

$\alpha-P 1$

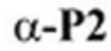

\section{Ponceau staining}

Figure 2: Anti-peptide 1 could detect the recombinant TcCyP21. rTcCyP21 protein could be detected by Western blot with the specific antibodies against peptide 1 ( $\alpha-P 1)$ but not with anti-peptide $2(\alpha-P 2)$ antibodies. Antibodies against the whole rTcCyP21 ( $\alpha-$ TcCyP21) were used as positive control.

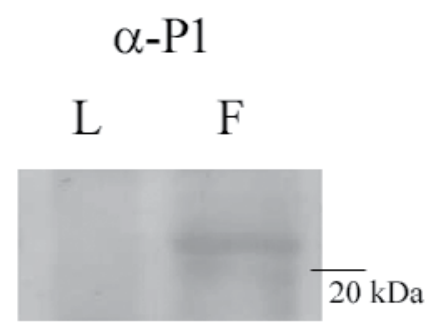

Figure 3: Anti -peptide 1 was able to detect native TcCyP21 in membraneenriched fractions. Anti-P1 was able to detect a unique band of the expected size for TcCyP21 in a membrane enriched fraction $(F)$, without the highabundance cytosolic proteins. However, native TcCyP21 could not be detected by anti-P1 in a total parasite lysate (L). (B) Anti-TcCyP21 failed to detect a unique specific band of $21.1 \mathrm{kDa}$ both against total parasite lysate $(\mathrm{L})$ and in a membrane-enriched fraction $(F)$. An arrow was used to indicate where the protein band corresponding to TcCyP21 was expected to be visualized.

which appears to be endoplasmic reticulum distribution and did not co-localize with the mitochondrial marker (Figure 4).

The subcellular localization of TcCyP21 was also confirmed by overexpression of TcCyp21-GFP in parasites in epimastigote stage (data not shown).

\section{Conclusions}

In the present work, we demonstrated that raising different and more specific antibodies against the $T c \mathrm{CyP} 21$ protein and increasing its abundance in the sample by subcellular fractionation and enrichment using digitonin, resulted in a successful strategy to confirm the expression of this low abundance cyclophilin.

This had not been possible before, especially considering that this

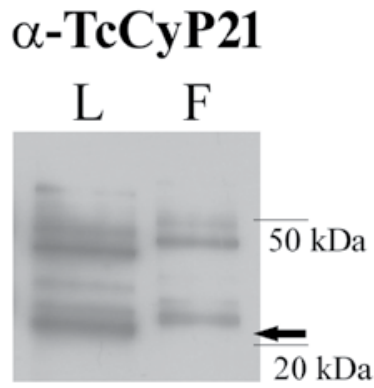

Figure 4: Anti -peptide 1 was able to confirm TcCyP21 perinuclear localization. Anti-P1 was used to confirm TcCyP21 subcellular localization by immunofluorescence, detected with a secondary antibody anti-mouse FITC (green). Mitotracker Deep Red was used as mitochondrial marker (red) and DAPI was used as nuclear staining (blue).

protozoan parasite expresses two other $\mathrm{CyPs}$ with high abundance (TcCyP19 and $T c \mathrm{CyP} 40)$ and conserved regions with TcCyP21. Although there was in silico evidence that this protein was expressed in the different stages of the parasite lyfe cycle, every attempt of detecting this low abundance TcCyP21 failed, when using total parasite lysate, even when the amount of cells per lane was increased 100 times. However, the TcCyP21 was successfully detected in membraneenriched fractions, confidently realted to an increased presence of this protein in the sample. Other biological samples may present similar challenges with a small number of high-abundance proteins masking the low abundance proteins of interest. Working with less complex samples obtained by any suitable enrichment protocol, such as subcellular fractionation or immunoprecipitation, may alleviate these challenges.

By using more specific antibodies against a selected peptide from TcCyP21, we were also able to avoid the cross-reactivity with the conserved regions among the protein family, which allowed us to obtain a tool for immunodetection of this protein.

The successful confirmation that this low-abundance TcCyP21 was expressed by the parasite reveals the potential of our approach for other biological samples of interest.

\section{Acknowledgements}

P.L.B. was supported by a fellowship from CONICET. We thank Dr. Alicia Graciela Fuchs and CAECIHS for supporting N.A.M. This work was financed by ANLIS Carlos G. Malbrán and Focanlis 2014, PICTO-ANLIS 00136/11 and by National Scientific and Technical Research Council (CONICET) Grant PIP 2014.

\section{References}

1. Takahashi N, Hayano T, Suzuki M (1989) Peptidyl-prolylcis-trans isomerase is the cyclosporinA-binding protein cyclophilin. Nature 337: 473-475.

2. Fischer G, Wittmann-Liebold B, Lang K, Kiefhaber T, Schmid FX (1989) Cyclophilin and peptidyl-prolyl cis-trans isomerase are probablyidentical proteins. Nature 337: 476-478.

3. Galat, Andrzej (2003) Peptidyl prolyl cis/trans isomerases (immunophilins) biological diversity-targets-functions. Current Topics in Medicinal Chemistry 3: 1315-1347.

4. Handschumacher RE, Harding MW, Rice J, Drugge RJ, Speicher DW (1984) Cyclophilin: a specific cytosolic binding protein for cyclosporin A. Science 226 : 544-547.

5. Schneider H, Charara N, Schmitz R, Wehrli S, Mikol V, et al. (1994) Human cyclophilin C: primary structure, tissue distribution, and determination of binding specificity for cyclosporins. Biochemistry 33: 8218-8224. 
Citation: Bustos PL, Perrone AE, Milduberger NA, Bua J (2015) Improved Immuno-Detection of a Low-Abundance Cyclophilin Allows the Confirmation of its Expression in a Protozoan Parasite. Immunochem Immunopathol 1: 103. doi: 10.4172/2469-9756.1000103

6. Bergsma DJ, Eder C, Gross M, Kersten H, Sylvester D, et al. (1991) The cyclophilin multigene family of peptidyl-prolyl isomerases. Characterization of three separate human isoforms. The Journal of Biological Chemistry 266: 23204-23214.

7. Colley NJ, Baker EK, Stamnes MA, Zuker CS (1991) The cyclophilin homolog ninaA is required in the secretory pathway. Cell 67: 255-263.

8. Teigelkamp S, Achsel T, MundtC, Gothel SF, Cronshagen U, et al. (1998) The $20 \mathrm{kD}$ protein of human [U4/U6.U5] tri-snRNPs is a novel cyclophilin that forms a complex with the U4/U6-specific $60 \mathrm{kD}$ and $90 \mathrm{kD}$ proteins. RNA 4: 127-141.

9. Anderson SK, Gallinger S, Roder J, Frey J, Young HA, et al. (1993) A cyclophilin related protein involved in the function of natural killer cells. Proc Natl Acad Sci USA 90: 542-546.

10. Yokoyama N, Hayashi N, Seki T, Pante N, Ohba T, et al. (1995) A giant nucleopore protein that binds Ran/TC4. Nature 376: 184-188.

11. Dolinski K, Muir S, Cardenas M, Heitman J (1997) All cyclophilins and FK506 binding proteins are individually and collectively, dispensable for viability in Saccharomyces cerevisiae. Proc Natl Acad Sci USA 94: 13093-13098.

12. Borel JF, Feurer C, Gubler HU, Stahelin H (1994) Biological effects of cyclosporine A: a new anti lymphocytic agent. Agents Actions 43: 179-186.

13. Galat A, Bouet F (1994) Cyclophilin B is an abundant protein whose conformation is similar to that of cyclophilin A. FEBS Lett 347: 31-36.

14. Kieffer LJ, Thalhammer T, Handschumacher RE (1992) Isolation and characterization of a 40-kDa cyclophilin-related protein. J Biol Chem 267: 55035507.

15. Bell A, Monaghan P, Page AP (2006) Peptidyl-prolylcis-trans isomerases (immunophilins) and their roles in parasite biochemistry, host-parasite interaction and antiparasitic drug action. Int J Parasitol 36: 261-276.

16. Potenza M, Galat A, Minning TA, Ruiz AM, Duran R, et al. (2006) Analysis of the Trypanosoma cruzi cyclophilin gene family and identification of cyclosporine A binding proteins. Parasitology 132: 867-882.
17. Kedia K, Nichols CA, Thulin CD, Graves SW (2015) Novel "omics" approach for study of low-abundance, low-molecular-weight components of a complex biological tissue: regional differences between chorionic and basal plates of the human placenta. Anal Bioanal Chem. Sep 8.

18. Filip S, Vougas K, Zoidakis J, Latosinska A, Mullen W, et al. (2015) Comparison of Depletion Strategies for the Enrichment of Low-Abundance Proteins in Urine. PLoS One 10: e0133773.

19. Gupta R, Wang Y, Agrawal GK, Rakwal R, Jo IH, et al. (2015) Time to dig deep into the plant proteome: a hunt for low-abundance proteins. Front Plant Sci 6: 22.

20. Doneanu CE, Anderson M, Williams BJ, Lauber MA, Chakraborty A, et al. (2015) Enhanced Detection of Low-Abundance Host Cell Protein Impurities in High-Purity Monoclonal Antibodies Down to $1 \mathrm{ppm}$ Using Ion Mobility Mass Spectrometry Coupled with Multidimensional Liquid Chromatography. Anal Chem. Sep 10

21. Kotler SA, Brender JR, Vivekanandan S, Suzuki Y, Yamamoto K, et al.(2015) High-resolution NMR characterization of low abundance oligomers of amyloid- $\beta$ without purification. Sci Rep 5: 11811.

22. Cannata JJ, Cazzulo JJ (1984) Glycosomal and mitochondrial malate dehydrogenases in epimastigotes of Trypanosoma cruzi. Molecular and Biochemical Parasitology 11: 37-49.

23. Laemmli UK (1970) Cleavage of structural proteins during the assembly of the head of bacteriophage T4. Nature 227: 680-685.

24. Verdun RE, Di Paolo N, Urmenyi TP, Rondinelli E, Frasch AC, et al. (1998) Gene discovery through expressed sequence Tag sequencing in Trypanosoma cruzi. Infect Immun 66: 5393-5398.

25. Agüero F, Abdellah KB, Tekiel V, Sánchez DO, González A (2004) Generation and analysis of expressed sequence tags from Trypanosoma cruz trypomastigote and amastigote cDNA libraries. Mol Biochem Parasitol 136: 221-225.

26. http://www.cbs.dtu.dk/services/BepiPred/ 